\title{
An approach to open source model on the collaborative construction in human civilization
}

\author{
Chih-Ming Chien ${ }^{1 *}$, June-Hao Hou ${ }^{2}$ \\ ${ }^{1,2}$ Graduate Institute of Architecture, National Chiao Tung University, Hsinchu, Taiwan
}

\section{Keywords \\ Open source \\ Vernacular architecture General contractor \\ Co-operative housing \\ Humanitarian architecture}

Received: 22 Agust 2017

Accepted: 18 October 2017

Published: 13 February 2018

\begin{abstract}
Open source has gradually gained prevalence in the architectural industry in recent years. The earliest concept of open source has been observed in vernacular architecture. However, obvious discrepancies can be discerned between vernacular and modern architecture, such as the use of currency in acquiring resources for contemporary, the complex piping, wiring, and electrical machinery of the modern building, and the high specialization of modern society. A literature review and a case study approach were adopted in the present study to collate three models that were sequentially developed and implemented from the beginning of human civilization, specifically, the collaborative construction employed by the common people in traditional settlements, the general contractor and the Co-operative Housing adopted following the Industrial Revolution, and the organization of humanitarian architecture applied in modern society. These models were analyzed to determine resource acquisition methods, collaborative construction methods, and life collaborative methods. The present study also conducted a preliminary analysis to develop a feasible collaborative construction model for modern open source architecture based on existing construction procedures. The proposed model contains the following three features: (1) it is a sharing economy platform for architecture; (2) it incorporates non-professional collaboration to restructure a professioncentered construction process; (3) and it adopts a time dollar concept to create a system of service sharing.
\end{abstract}

(C) 2018 The Author(s). Published by TAF Publishing.

\section{INTRODUCTION}

Open source architecture can be traced back to vernacular architecture [1], wherein design and construction are merged into one and closely linked to everyday life. Following the Industrial Revolution, design and construction were separated with the prevalence of the professional division of labor [2]. In ancient settlements, people used to build houses in accordance with the laws of nature [3], promote group cooperation through gift [4] and barter economies [5], collect materials from nature, and make hand tools [6]. After the Industrial Revolution, people turned to houses that were quantitative, modularized, safe, and solid. They employed professionals under the frameworks of capitalist economies and contract-based partnerships, and made artificial building materials as well as industrial machines and tools [7]. In order to address the housing issues arising from wealth inequality and extreme climate, some contemporary organizations working in humanitarian architecture have tried to engage the public in housing construction by using a cloud-based approach that simplifies the collaboration among stakeholders [8]. In current times, the architecture organizations that aim far to reach remote or disasteraffected areas can meet challenges when they try to fulfill pressing local construction needs because of lagging infrastructure, such as those related to power supply, fuel availability, and road connection [9]. Thanks to the open source movement, these architecture organizations have seen new possibilities $[10,11]$. In this study, we review the history of human civilization to examine closely how ancient settlements carried out construction with less dependence on the urban construction system, how architectural professionals after the Industrial Revolution achieved high-strength and

\footnotetext{
${ }^{*}$ Corresponding author: Chih-Ming Chien

†email: cmchien@arch.nctu.edu.tw
} 
safe construction by conducting construction management, and how contemporary humanitarian architecture organizations have formed successful construction strategies by employing flexible manpower layouts and integrating different construction systems. From this analysis, we summarize, compare, and outline the three phases of collaborative construction.

Most early discussions about open-source architecture, as seen in previous literatures, have focused on open-source designs, computer technology application, and development trends. Contemporary research has focused on the design aspect of open sourcing. For example, the winner of the 2016 Pitzker Architecture Prize, Alejandra Aravena, made his award-winning schematics available to the public [12]; WikiHouse set parameters to facilitate Open Source Design (OSD); and OpenBricks and PaperHouses developed a sustainable online OSD platform. To supplement the limited historical review, literatures discussing construction from the viewpoints of history and archeology are referred to in this study. Nevertheless, available papers on the history of construction have mostly focused on buildings in the western world; the locations of the architecture discussed have not been geographically diverse. To address this literature gap, this study turns to literatures focused on vernacular architecture. Additionally, considering that the available studies on organizations engaging in humanitarian architecture are mainly in the form of collections of works, and less relevant to manpower strategies and construction systems, this study consults such organizations' official websites and the author's personal experience gained from working in three of these organizations.

Few studies have tackled Open Source Construction (OSC) directly, resulting in a lack of understanding among people of the stage of construction to initiate once schematics have been acquired. This paper aimed to develop three collaborative construction models; one for traditional vernacular architecture, one for post-Industrial Revolution construction systems, and one for contemporary humanitarian architecture, and to create an open-source collaborative construction model that meets current demands.

This study makes a contribution by identifying literatures about open-source construction; naming the five pillars of open-source construction (manpower, construction cooperation, collaborative life, materials, and tools ); clarifying the distinctness of collaborative construction; and providing an open-source model for collaborative construction that enables contemporary people to participate in and optimize collaborative construction through open sources depending on their respective resources, needs, and back- grounds. In addition, an approach where people trade in time instead of money is provided, thereby shifting the basis of construction from consumerism back to its original nature as a part of living. By proposing a sharing economy along the construction process, this study encourages the development of an open platform where people share tools, exchange building materials, and coordinate manpower. In terms of research impact, this study attempts to inspire people to, when developing open-source architecture, consider an open construction process and apply open discussions on blueprints, so as to realize truly open-source architecture from design to project completion. By acquiring opensource blueprints, people can complete their construction projects by means of group and cloud-based collaboration without excessive dependence on general contractors who use closed-source technologies.

\section{LITERATURE REVIEW}

OSD has been extensively discussed in recent researches. Topics, such as collaboration platforms for the open-source design of residence houses [13], the impact of open-source design on environmental sustainability [14], and the story of Alejandro Aravena, a winner of the renowned Pritzker Architecture Prize, opening his blueprints for public access, have drawn much attention [12].

Studies on open-source construction can be divided into two groups. The first group is about construction. In particular, these papers discuss the openness of building information from the perspective of building information modeling. Examples of topics in this group include the early introduction of OPEN BIM in design [15]; the management of construction knowledge using the SocioBIM platform [16]; and the analysis of green building based on the BIM collaboration platform of open design [17]. The second group of studies is about architecture, particularly the development of ways to assemble building materials through parametric design, such as OpenStructures using normal architectural hardware, and WikiHouse that involves cutting wooden splints into tenons using CNC. Regarding vernacular architecture, as emphasized in the recent relevant researches to further architecture in the future, developing contemporary open-source architecture applications by learning from the cooperation practices seen in ancient settlements would be a sustainable approach [18].

Open-source architecture originated from ancient settlements. After the Industrial Revolution, group cooperation construction implemented in ancient settlements transformed into competition among developers [19]. People developed construction proprietary expertise like construc- 
tion methods, construction management, contract-based partnership [20], etc. While competition, built on the opacity of information, has led to a forward leap in technology, the resulting overexploitation has brought about extreme climate, which is believed to be responsible for the great wealth disparity between rural and urban areas [21]. To address this issue, some contemporary architecture organizations are rethinking what sustainable construction means in a humanistic sense and figuring out how to achieve this by combining the various post constructions emerging after the Industrial Revolution with the group cooperation seen in ancient settlements [22].

This literature review is focused on this process. It discusses the collaborative construction of ancient settlements as examined in a large number of literatures published in Europe, Asia, and Africa. Examples from Asia are the Hemudu Site in China, the yurts in Mongolia, and the historic villages of Shirakawa-go in Japan. Examples from Africa include the Great Zimbabwe in Zimbabwe, the Musgum settlement in Cameroon, and the Dogon settlement in
Mali. Examples from Europe include the Mammoths Huts, the Matera settlement, and the Trulli settlement. It discusses the collaborative construction among construction professionals as seen after the Industrial Revolution in the forms of general contractors in the UK market economy; cooperative housings in the German social market economy; and small-scale gangs of craftsmen in Japan in response to postwar economic recovery. It examines the collaborative construction supported by humanitarian architecture organizations, as seen in many cases where organizations combine various construction systems. Examples of such organizations include the Rural Studio in the US that combines universities' carpentry shops, universities' architecture programs, and general contractors; Atelier-3 in Taiwan that draws together architecture firms, co-operative housing, and general contractors; and WikiHouse in the UK that links up makers, automated equipment manufacturers, and local craftsmen. Figure 1 shows timeline of this literature review in human civilization.

\section{Vernacular Architecture in Traditional Settlements}

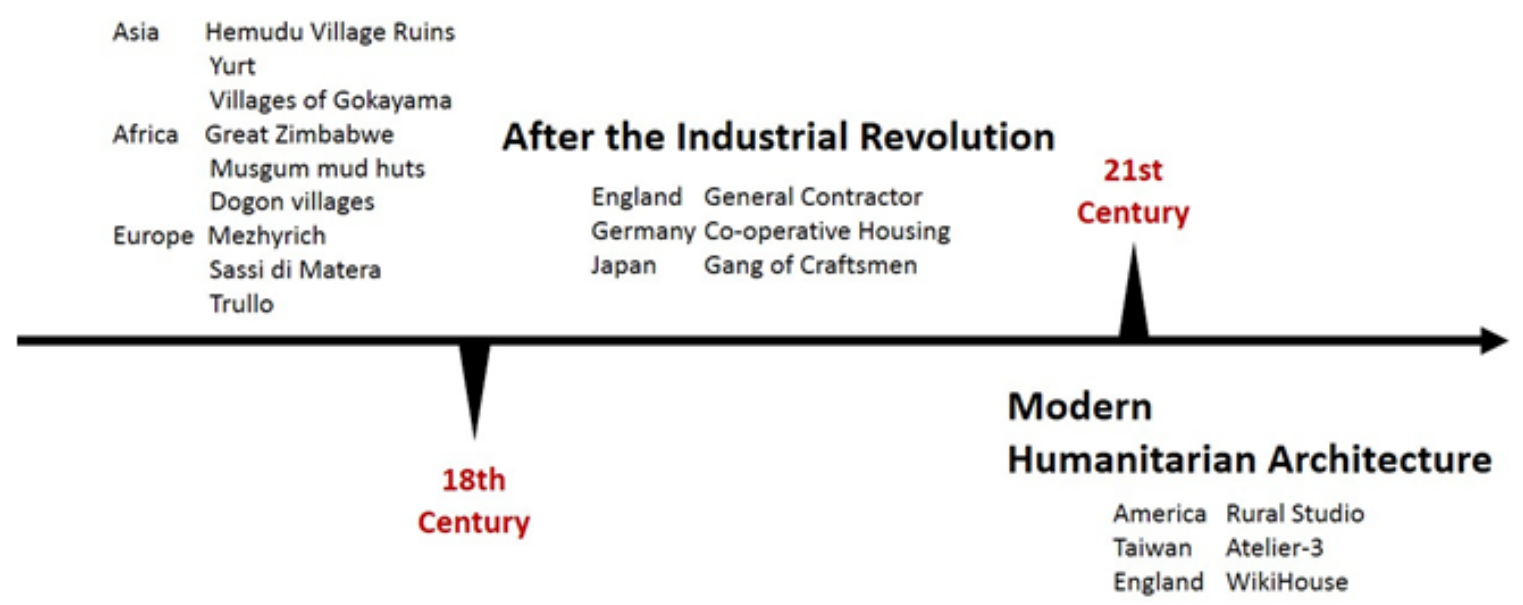

Fig. 1. Timeline of this literature review in human civilization

\section{A. Construction Models of Laypeople in T Settlements}

This study will explore cases through collected literature in the fields of archaeology, vernacular architecture, archi- tectural history, anthropology, ethnography, geography, and other fields. Nine traditional settlements, which have been studied extensively, were chosen. Their locations are shown in Table 1.

TABLE 1

VERNACULAR ARCHITECTURE IN TRADITIONAL SETTLEMENTS

\begin{tabular}{ll}
\hline \hline Asia & Hemudu Village Ruins (China), Yurt (Mongolia), Villages of Gokayama (Japan) \\
Africa & Great Zimbabwe (Zimbabwe), Musgum mud huts (Cameroon), Dogon villages (Mali) \\
Europe & Mezhyrich (Ukraine), Sassi di Matera (Italy), Trullo (Italy) \\
\hline \hline
\end{tabular}


1) Traditional settlements: Traditional Settlements is based on collective cooperation. For example, through hunting, farming, and collecting, overcome the environmental limitations and basic survival needs of individuals and develop a stable method of cooperative construction $[3,23]$. In life, according to the two economic definitions of effort and reward ratio which are gift economy [4] and barter economy [5], this study summarized three cooperation methods that developed along with cultural differences: Sharing Food, Relationship Help, and Exchange Labor. In construction, this study mercerized three common cooperation systems: clan commune training, family inheritance, and mentoring and apprenticeship. Through these three methods, technologies are passed from the professionals to the paraprofessionals and meanwhile, family or neighborhood members form a non-professional team to undertake non-professional and physical works in the construction process [24].

\section{B. Construction Models after the Industrial Revolution}

Heavy machinery and dedicated material factories emerged following the Industrial Revolution. People began dividing labor based on specialization, and professional-based collaborative construction groups, primarily comprising largescale general contractors and small-scale gangs of craftsmen, formed in free market economies. By comparison, professional-non-professional cooperative housing models formed in social market economies. As shown in this section, three construction models were developed based on the construction professionals of England, Germany, and Japan.

TABLE 2

BET SURFACE AREA OF SOLIDS USED IN EXPERIMENT

\begin{tabular}{ll}
\hline \hline England & General Contractor \\
Germany & Co-operative Housing \\
Japan & Gang of Craftsmen \\
\hline \hline
\end{tabular}

1) General contractors: The first material processing plant opened in 1801. The plant used machines to produce more resilient yet more affordable building materials. Employees in the factory were trained in the operation of the machines rather than in production, and management strategies were implemented to achieve scale and quality. Regarding tools, advancements in electricity and steelmaking enabled the development of sizable construction machines to facilitate the construction of buildings and facilities on a large scale [7]. The general contractors involved in construction used contracts to set prices and quantify work- load, and landowners engaged in partnerships with general contractors through contracts. General contractors then outsourced all or a portion of the workload to subcontractors [20]. Early contractors were factories that were capable of maintaining a stable supply of materials or craftsmen with relevant construction or machine operation experience. In terms of manpower, early apprenticeship models were thought to hinder technological reform, leading to the emergence of three parties that made collaborative construction possible. The first party was the investors, such as sales or distribution tycoons, landlords, or nobles. The second party was the architecture professionals, such as architects, factory managers, and machine operators. The third party was the labor, such as farmers, migrant workers, and children.

2) Cooperative housing: Cooperative housing was introduced in Germany in 1862 to help proletarians and the working class to secure housing through economic cooperation and aggregated housing. After World War II, public housing became the primary form of housing in Germany [25]. Generally, cooperative housing groups comprise at least one architect or professional, who is responsible for the design and offers construction consultation. Supported by Germany's robust industrial backbone, people were less reliant on general contractors. The development of efficient building materials, such as those produced by the DYWIDAG System, created increased opportunities for nonprofessionals to participate in construction.

3) Gangs of craftsmen: A law was passed in Japan in the year 889 , regulating all government construction projects to be tendered to craftsmen. This law led to the prevalence of a cooperative system known today as a gang of craftsmen. After World War II, the rise in housing demands in Japan caused gangs of craftsmen, which primarily comprised of carpenters, to gradually evolve into general contractors [26]. Gangs of craftsmen generally focused on erecting the wooden framework. They then outsourced other tasks of the construction project to 30 types of professionals spanning across 20 specializations, with whom they had previously established long-term relations [27].

\section{Construction Models of Modern Humanitarian Archi- tecture}

Humanitarian architecture organizations are modern construction teams formed under the duress of environmental change, post-disaster reflection, and sustainability demands [8]. In this section, three examples of such organizations from Europe, Asia, and the United States are discussed. 
TABLE 3

BET SURFACE AREA OF SOLIDS USED IN EXPERIMENT

\begin{tabular}{ll}
\hline \hline America & Rural Studio \\
Taiwan & Atelier-3 \\
England & WikiHouse \\
\hline \hline
\end{tabular}

1) Rural studio: It is an undergraduate program of the School of Architecture. It entails the formation of designs and construction tasks through the interactions of teachers, students, and community residents [28]. In terms of manpower, the program comprises of professors, architects, carpenters, and construction supervisors. Para-professionals refer to students in their third or fifth year of university [29]. The program engages in collaborative construction through design-build programs, wherein the university collaborates with general contractors to compensate for the inadequacy of practical experience. For tools, a combination of the university's wood workshop and general contractors' machinery is applied. For materials, natural materials, waste, and modern building materials are used. In terms of collaborative life, specialized instructors are funded by the university and materials are funded by the residents. Students participate voluntarily and are responsible for their own food and accommodation.

2) Atelier-3: The studio achieves collaborative construction by working with architectural firms, general contractors, and cooperative housing organizations. The studio primarily focuses on disaster-ridden regions, wherein disaster victims work for relief, general workers work on a volunteer basis, and professionals work on demand. For tools, light steel processing equipment, general contractors' machinery, and handheld power tools are primarily used. For materials, light steel, natural materials, and modern building materials are used [22]. In terms of resource acquisition, disaster reconstruction is typically funded through private donations. The government assists disaster victims in reclaiming land and offers low-interest loans.

3) Wiki house: WikiHouse offers a set of OSD principles that enable local architectural teams to develop designs and then submit their schematics to digital manufacturing vendors to cut the materials. All participants follow the operating manual provided by WikiHouse to achieve collaborative construction [30]. For tools, CNC and wooden tools are largely used. For materials, modern materials are applied. Manpower comprises of WikiHouse, local architectural teams, digital manufacturing vendors, volunteers, and local residents.

\section{RESEARCH METHODS}

This study was conducted using a literature review and case analysis. In order to understand the impact of ancient settlements and professionals on construction, induction was applied as a part of the literature review method to identify the five common pillars of construction: manpower, construction cooperation, collaborative life, materials, and tools. A comparison was then used to determine the differences among the five pillars, so as to set up the foundation of the proposed model. To investigate humanitarian architecture organizations, a case analysis was performed to extract the components of the five pillars.

The selection and collection of literatures: on the subject of ancient settlements, the targets were the literatures about the five construction pillars that not only had been extensively published but also could corroborate one another. In terms of construction professionals, the cases targeted were new construction regimes that were established in human history as a result of the transformation of construction technologies and cooperation patterns, such as general contractors becoming active in the market economy after the Industrial Revolution, co-operative housing in the social market economy, and small-scale gangs of craftsmen in response to postwar economic changes. Regarding humanitarian architecture organizations, we sought cases that combined two or more ways of construction cooperation. In this last part, since numerous cases were found usable, this study focused on three cases with which the author was engaged in person. In terms of the literature collection, in addition to architecture books, journals, and conference papers, we also consulted the official websites, speeches, and presentations of humanitarian architecture organizations. Lastly, based on the construction pillars and fundamental components identified using the literature review and case analysis, a complete model was created using the model method to describe the process of collaborative construction that happened in the aforementioned cases and to act as a prototype model to be used by future studies on opensource construction. 


\section{A. Collaborative Construction Model in Traditional Set- tlements}

These models can be further characterized by three main units: Manpower, Collaborative Construction, and Life. According to the different cultural practices to obtain Professional, Paraprofessional, and non-professional assistance, Sharing Food, Relationship Help, and Exchange Labor can solve the needs of life. Ultimately, it leads to driving people to inherit technology and training (Figure 2). Another two sub-units: Tools and Materials. Laypeople used animal teeth or bones to fabricate tools. Eastern European tribes used the tusks of wooly mammoths or the antlers of deer to make hammers [31], and settlements in Hemudu, China used animal bones to make a variety of tools. Fire was also used as a tool in construction. Laypeople in the villages of Shirakawa-go, Japan smoked wood structures to prevent corrosion [32], and villages in Zimbabwe, Africa used fire in metallurgy [33]. Some laypeople used livestock as tools, such as the use of cattle to draw carts in Mongolia [34], and some used their own bodies as tools, such as the use of adult bodies as a unit of measure in Africa. Natural resources were also widely used to fabricate tools, such as the use of stone shovels in a number of European settlements [35].

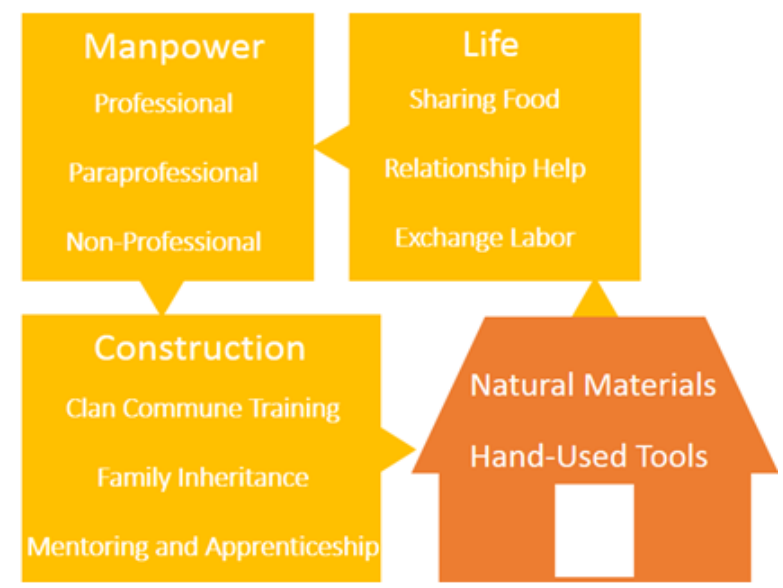

Fig. 2. Collaborative construction model in traditional settlements

\section{B. Collaborative Construction Model after the Indus- trial Revolution}

Compared to traditional settlements, post-Industrial Revolution construction professionals can be further characterized into operators, craftsmen, and artisans. Habraken defined construction as a system with clear hierarchies [36]. This system enables people to effectively divide labor to complete construction tasks, wire and pipe distribution, and interior renovation. Large quantities of modern materials, such as cement, steel, and glass, were employed in this era, and the prevalence of electricity enabled power tools to gradually replace hand-powered tools. Moreover, animal- drawn vehicles were replaced by fuel-powered options (Figure 3).

\section{Collaborative Construction Model of Humanitarian Architecture}

In humanitarianism-based collaborative construction, projects typically steer away from local industrial development or government-run projects [2]. The projects typically encourage resident participation to achieve collaborative construction, similar to traditional settlements. Professionals are carefully employed to develop techniques and foster local, autonomous construction ability [37].

\begin{tabular}{ll}
\hline \hline Operator & People trained in a specific task or machine, responsible for the operational work of a specific task \\
Craftsman & Specialized and experienced professionals that are able to develop new techniques \\
Artisan & Specialized and experienced professionals that are able to create unique functionality, art, or aesthetics \\
\hline \hline
\end{tabular}




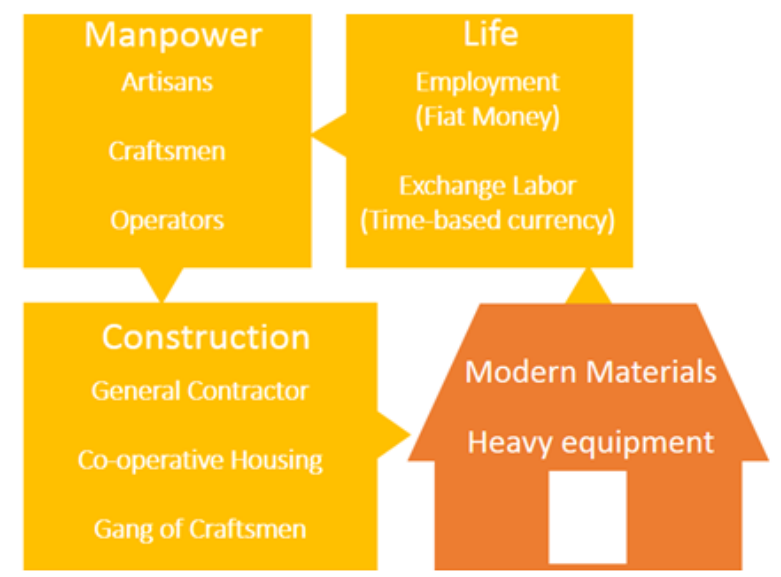

Fig. 3. Collaborative construction model after the industrial revolution

In terms of collaborative life, professionals typically work on demand and non-professionals work voluntarily or for relief (Figure 4). Moreover, resident participation is encouraged to enhance food sharing, relationship help, and labor exchange. For tools, handheld tools coupled with general contractors' machinery are largely used on the construction site. This is made possible by the simplification of techniques and the application of digital manufacturing equipment beforehand. For materials, modern buildings materials, natural materials, and recycled waste are used. In terms of resource acquisition, humanitarian architecture organizations largely work in regions with limited resources. Therefore, most of the resources are subsidized by the government or received through donations or universities.

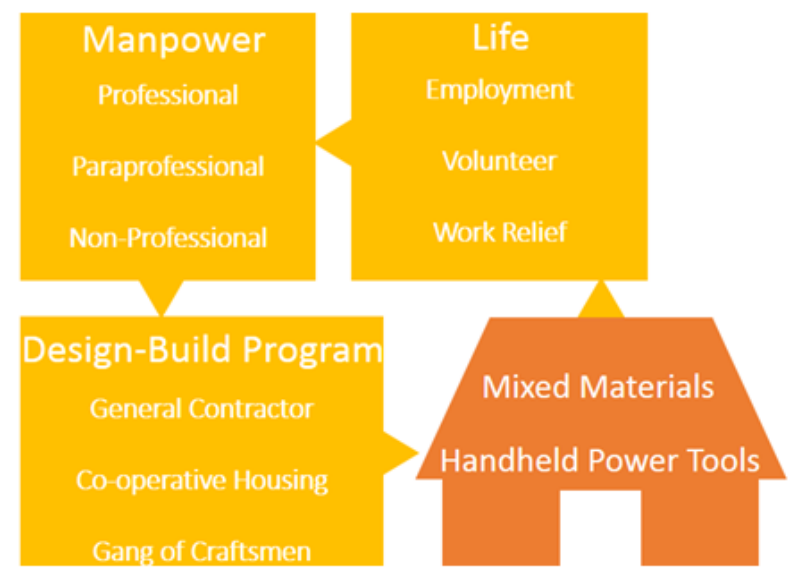

Fig. 4. Collaborative construction model of humanitarian architecture

\section{PRELIMINARY ANALYSIS OF EXISTING OPEN-SOURCE CONSTRUCTION MODEL}

In this section, the models developed throughout human civilization are summarized to identify individual construction elements. These elements and their dominantsubordinate relationships are then used to create a systematic construction model that features the collaborative characteristics of laypeople in traditional settlements while retaining the characteristics of modern, professional construction models, and digital manufacturer models.

The five frameworks are listed under the Main Structure, Wire/Piping Configuration, and Interior Renovation systems. This layout establishes the basic collaborative construction model. Once the user decides on the model, they could flexibly combine the elements and control the cost. The elements are shown in Table 5. 
TABLE 5

OPEN-SOURCE MODEL ON THE COLLABORATIVE CONSTRUCTION ELEMENTS

\begin{tabular}{|c|c|c|c|c|}
\hline & Professional & Artisans & Craftsmen & Operators \\
\hline \multirow[t]{2}{*}{ Manpower } & Paraprofessional & Apprentices & College Students & Design Assistant \\
\hline & Non-Professional & Laypeople & & \\
\hline \multirow[t]{2}{*}{ Collaborative } & Main Structure & Laypeople, General & & \\
\hline & & Contractor, Co-operative & & \\
\hline \multirow[t]{5}{*}{ Construction } & Wire/Piping Configuration & Housing Laypeople, General & & \\
\hline & & Contractor, Co-operative & & \\
\hline & Interior Renovation & Design-Build & & \\
\hline & & Housing teams, & & \\
\hline & & College of Architecture & & \\
\hline Collaborative & Gift Economy & Sharing Food & Relationship Help & Volunteer \\
\hline \multirow[t]{2}{*}{ Life } & Barter Economy & & Exchange Labor & \\
\hline & Fiat Money & Employment & Work Relief & \\
\hline \multirow[t]{3}{*}{ Materials } & Natural Materials & Organic matter & & \\
\hline & Modern Materials & Artificial building materials & & \\
\hline & Conveyances & Animal transport & Fuel Conveyance & \\
\hline \multirow[t]{2}{*}{ Tools } & Mechanical & Power Tools & Heavy equipment & Automation \\
\hline & Non-Mechanical & & Hand-Used Tools & \\
\hline
\end{tabular}

\section{DISCUSSION}

From vernacular architecture to the history of western construction as discussed in previous researches, the changes in collaborative life, from the sharing of food, relationships based on mutual help, and labor exchange to the hiring of workers, volunteering, and work relief, reflect the economic changes in human civilization: gift economy, barter economy, and monetization. In terms of construction cooperation, the progress from youth training, family heritage, and mentoring in ancient settlements to general contractors, cooperatives, and gangs of craftsmen to the contemporary introduction of university programs, the driving force of makers, and digital manufacturing factories signals a turn to inclusivity in collaborative construction. As for manpower, thanks to cloud-based collaboration, a more extensive participation of non-professionals in construction has become possible because the limits of time and space associated with previous labor-intensive approaches have been eliminated. With regard to tools, natural materials, such as animal bones, rocks, and animal power, as the major sources in ancient times have been replaced by the domination of electric machines and petrol vehicles in modern times. Further, materials that were obtained locally are now processed in factories into artificial materials.

Different from the previous researches on open-source architecture, this study features a model that can run in different open-source design schemes, without the limitations of construction systems and rules, while allowing non-professionals to have better access to options of manpower layouts, tools, and materials, and to better manage construction costs and time. Compared to BIM, as discussed in previous researches, despite its options in terms of collaborative life, this model can only provide semantic information rather than geometric information.

In terms of research inference, people can access opensource blueprints from the Internet, use this model to review the resources that they can afford, and further promote group cooperation, so as to develop real open-source architecture from design to construction. Users are able to acknowledge three major pieces of the construction information, specifically, which procedures are needed, how to engage in human cooperation, and how to control tools and materials to minimize cost. In addition, spurred on by the incitement of future makers, smarter tools can be obtained more easily, which would lead to more convenient and rapid completions of collaboration without an excessive dependence on general contractors who use closed-source technologies. The conventional way of construction currently employed by construction companies can thus be changed gradually. As for research impact, the model can not only be applied to construction projects, using OSD through a sharing economy, but also encourage people to develop more diverse, down-top group cooperation and interaction, such as open platforms of shared tools, building material exchange, and manpower coordination. Throughout construction, no pecuniary exchange would be required, and people would 
only pay with their time for labor or expertise, engaging non-professional and inter-disciplinary talents, thereby reducing the use of capital and prompting interactions among members of all social strata.

In the case of research limitations, where natural materials are to be used in construction, communication between participants and the public sector would be required to address local building laws, such as provisions on fire-proof materials, structural strength, and so on. In addition, it is expected that this model would be less applicable in places where land acquisition is relatively difficult, such as urban areas, and where land is expensive. Future studies may consider the following three practical recommendations: (1) OPEN BIM could be incorporated for construction information management, thereby better positioning the model for dealing with the details of more complicated construction designs; (2) this model could be built into a platform for open-source collaboration and particularly for collaborative construction using Github; and (3) an open database of various tools and materials used in small-scale construction could be developed, thereby supporting the construc- tion of structures based on different natural materials, such as brick, wood, or bamboo.

\section{RESEARCH CONTRIBUTIONS}

\section{A. Construction Process that Focuses on Reconfiguring Professionals}

The proposed model encourages general contractors to develop customized construction strategies from the bottom up and facilitates people in re-discovering the nature of construction and the fun in cooperation.

\section{B. Cooperative Model that Uses Time as a Currency}

This model encourages participants to use time currency as an alternative to the money-driven services provided in modern life, reviving the "vernacular architecture is life" attitude and overturning consumption ideologies.

\section{Prototype for a Shared Economy in Architecture}

It changes entire capital system rather than just construction systems. The proposed model not only encourages the sharing of professional construction knowledge but also urges participants to develop tools for sharing, exchange building materials, and create open-source platforms for human collaboration.

\section{REFERENCES}

[1] C. Ratti and M. Claudel, Open Source Architecture. New York, NY: Thames \& Hudson London, 2015.

[2] C. Alexander, H. Davis, J. Martinez, and D. Corner, The Production of Houses. Oxford, UK: Oxford University Press, 1985, vol. 4.

[3] P. Oliver, Dwellings: The Vernacular House World Wide. London, UK: Phaidon London, 2003.

[4] D. Cheal, The Gift Economy. New York, NY: Routledge, 2015.

[5] A. Sullivan, Economics: Principles in action. Upper Saddle River, NJ: Pearson Prentice Hall, 2003.

[6] A. S. Steen, B. Steen, and E. Komatsu, Built By Hand: Vernacular Buildings Around the World. Layton, UT: Gibbs Smith, 2003.

[7] W. R. Haycraft, "History of construction equipment," Journal of Construction Engineering and Management, vol. 137, no. 10, pp. 720-723, 2011. doi: 10.1515/9783110977684-010

[8] C. Sinclair and K. Stohr, Design Like You Give A Damn: Architectural Responses To Humanitarian Crisis. New York, NY: Thames \& Hudson, 2006.

[9] H. Z. Jacobson, C. Bruderlein, N. Pollock, E. Weizman, and S. Ban, Shigeru Ban: Humanitarian Architecture. New York, NY: Aspen Art Press, 2014.

[10] K. Ye, H. Lu, and W. Chao, "Grey forecast models of manpower demand for pilots in Taiwan," International Journal of Applied and Physical Sciences, vol. 2, no. 3, pp. 85-93, 2016. doi: 10.20469/ijaps.2.50005-3

[11] J. Rifkin, The Zero Marginal Cost Society: The Internet of Things, The Collaborative Commons, and The Eclipse of Capitalism. New York, NY: St. Martin's Press, 2014.

[12] R. Peltason and G. O. Yan, Architect: The Pritzker Prize Laureates in Their Own Words. New York, NY: Black Dog \& Leventhal, 2017.

[13] T. T. Lo, M. A. Schnabel, and Y. Gao, "Modrule: A user-centric mass housing design platform," in International Conference on Computer-Aided Architectural Design Futures, Heidelberg, Germany, 2015. 
[14] J. Bonvoisin, "Implications of open source design for sustainability," in Conference on Sustainable Design and Manufacturing, Berlin, Germany, 2016.

[15] J. Choi, H. Kim, and I. Kim, "Open bim-based quantity take-off system for schematic estimation of building frame in early design stage," Journal of Computational Design and Engineering, vol. 2, no. 1, pp. 16-25, 2015. doi: 10.1016/j.jcde. 2014.11.002

[16] R. Grover and T. M. Froese, "Knowledge management in construction using a sociobim platform: A case study of ayo smart home project," Procedia Engineering, vol. 145, pp. 1283-1290, 2016. doi: 10.1016/j.proeng.2016.04.165

[17] T. El-Diraby, T. Krijnen, and M. Papagelis, "Bim-based collaborative design and socio-technical analytics of green buildings," Automation in Construction, vol. 82, pp. 59-74, 2017. doi: 10.1016/j.autcon.2017.06.004

[18] I. Linkov, Sustainable Cities and Military Installations. Berlin, Germany: Springer, 2013.

[19] W. Addis, Building: 3000 Years of Design Engineering and Construction. London, UK: Phaidon Press, 2007.

[20] A. Becchi, M. Corradi, F. Foce, and O. Pedemonte, Construction History: Research Perspectives in Europe. Turin, Italy: Kim Williams Books, 2004.

[21] A. Lepik, Small Scale, Big Change: New Architectures of Social Engagement. New York, NY: The Museum of Modern Art, 2010.

[22] E. Charlesworth, Humanitarian Architecture: 15 Stories of Architects Working After Disaster. New York, NY: Routledge, 2014.

[23] B. Rudofsky, Architecture Without Architects: A Short Introduction to Non-Pedigreed Architecture. New York, NY: Museum of Modern Art Press, 1964.

[24] C. M. Chien and J. H. Hou, "Tooling applications in the collaboration construction of traditional settlements in East Asia," International Journal of Applied and Physical Sciences, vol. 2, no. 3, pp. 79-84, 2016. doi: 10.20469/ijaps.2.50004-3

[25] S. Moreau and A. Pittini, Profiles of a Movement: Co-operative Housing around the World. East London, South Africa: ICA Housing, 2012.

[26] H. Sumikura and S. Matsumura, "Characteristics of small housing builders from the point of view of business structure," Journal of Architecture and Planning, vol. 74, no. 639, pp. 1125-1131, 2009.

[27] S. Matsumura and H. Sumikura, "The production mechanism from the viewpoint of resource selection and arrangement," Journal of Architecture and Planning, vol. 76, no. 659, pp. 123-130, 2011.

[28] A. O. Dean, L. Chua, and C. Robinson, Rural studio: Samuel Mockbee and An Architecture of Decency. New York, NY: Princeton Architectural Press, 2002.

[29] A. O. Dean, Proceed and Be Bold: Rural Studio After Samuel Mockbee. New York, NY: Princeton Architectural Press, 2005.

[30] A. Parvin and E. O’Neil, "Open source wikihouse disrupts traditional design," Carnegie Council: Policy Innovations, vol. 3, no. 5, pp. 23-30, 2012.

[31] L. Iakovleva, F. Djindjian, E. Maschenko, S. Konik, and A.-M. Moigne, "The late upper palaeolithic site of gontsy (Ukraine): A reference for the reconstruction of the hunter gatherer system based on a mammoth economy," Quaternary International, vol. 255, no. 9, pp. 86-93, 2012. doi: 10.1016/j.quaint.2011.10.004

[32] N. Wada, M. Suzuki, and M. Yokohari, "A study on the maintenance system of thatched roofs in gokayama ainokura village, japan," Journal of the Japanese Institute of Landscape Architecture (Japan), vol. 70, no. 5, pp. 689-694, 2007. doi: 10.5632/jila.70.689

[33] S. Chirikure and I. Pikirayi, "Inside and outside the dry stone walls: revisiting the material culture of great zimbabwe," Antiquity, vol. 82, no. 318, pp. 976-993, 2008. doi: 10.1017/s0003598x00097726

[34] X.-x. Gao, H.-k. Zheng, and G. JIN, "Green design propetry of mongolian yurts," Journal of Inner Mongolia Agricultural University (Natural Science Edition), vol. 30, no. 1, pp. 109-113, 2009.

[35] N. Cardinale, G. Rospi, and A. Stazi, "Energy and microclimatic performance of restored hypogeous buildings in south italy: the "Sassi" district of Matera," Building and Environment, vol. 45, no. 1, pp. 94-106, 2010. doi: 10.1016/j.buildenv. 2009.05.017

[36] N. J. Habraken, Variations: The Systematic Design of Supports. New York, NY: Laboratory of Architecture and Planning at MIT, 1976.

[37] N. Hamdi et al., Housing Without Houses: Participation, Flexibility, Enablement. Southampton Row, UK: Intermediate Technology Publications Ltd (ITP), 1995. 